Final Report

\title{
GRADUATE AUTOMOTIVE TECHNOLOGY EDUCATION (GATE) CENTER
}

(Cooperative Agreement Number DE-FC02-98CH10956)

The University of Tennessee, Knoxville

Knoxville, Tennessee

Submitted to:

Mr. Steven Cooke

U.S. Department of Energy

National Energy Technology Laboratory

3610 Collins Ferry Road

P.O. Box 880

Morgantown, WV 26507-0880

Submitted by:

Dr. Jeffrey W. Hodgson

Professor Emeritus and GATE Director

And

Dr. David K. Irick

Professor and GATE Director

414 Dougherty Engineering Building

The University of Tennessee

Knoxville, TN 37996-2210

June 14, 2006 


\section{DISCLAIMER}

This report was prepared as an account of work sponsored by an agency of the United States Government. Neither the United States Government nor any agency thereof, nor any of their employees, makes any warranty, express or implied, or assumes any legal liability or responsibility for the accuracy, completeness, or usefulness of any information, apparatus, product, or process disclosed, or represents that its use would not infringe privately owned rights. Reference herein to any specific commercial product, process, or service by trade name, trademark, manufacturer, or otherwise does not necessarily constitute or imply its endorsement, recommendation, or favoring by the United States Government or any agency thereof. The views and opinions of authors expressed herein do not necessarily state or reflect those of the United States Government or any agency thereof. 


\section{Summary}

The Graduate Automotive Technology Education (GATE) Center at the University of Tennessee, Knoxville has completed its sixth year of operation. During this period the Center has involved thirteen GATE Fellows and ten GATE Research Assistants in preparing them to contribute to advanced automotive technologies in the center's focus area: hybrid drive trains and control systems. Eighteen GATE students have graduated, and three have completed their course work requirements. Nine faculty members from three departments in the College of Engineering have been involved in the GATE Center.

In addition to the impact that the Center has had on the students and faculty involved, the presence of the center has led to the acquisition of resources that probably would not have been obtained if the GATE Center had not existed. Significant industry interaction such as internships, equipment donations, and support for GATE students has been realized. The value of the total resources brought to the university (including related research contracts) exceeds $\$ 4,000,000$.

Problem areas are discussed in the hope that future activities may benefit from the operation of the current program. 


\section{Table of Contents}

Summary

$\begin{array}{ll}\text { Background } & 1\end{array}$

The UTK GATE Center - an Overview 1

UTK GATE Faculty $\quad 2$

The UTK GATE Curriculum 2

Recruitment of Students 3

The UTK GATE Students 3

Gate Fellows 4

GATE Research Assistants $\quad 5$

Industrial Interaction

FutureTruck $\quad 5$

DaimlerChrysler $\quad 6$

Visual Computing Systems $\quad 6$

Delphi 6

Fiat America $\quad 6$

Industrial Ceramic Solutions $\quad 6$

The NTRC

$\begin{array}{ll}\text { Value of Resources Obtained } & 7\end{array}$

$\begin{array}{ll}\text { Support from the University } & 7\end{array}$

Other UTK GATE Center Activities $\quad 7$

$\begin{array}{ll}\text { The UTK GATE Center Dedication Ceremony } & 7\end{array}$

Hybrid Electric Vehicle Displays $\quad 8$

Hybrid Electric Vehicle Seminar $\quad 8$

Summer Kids Program $\quad 8$

TAMA Seminar $\quad 8$

Problems Encountered $\quad 8$

Funding Uncertainties $\quad 8$

$\begin{array}{ll}\text { Research Support for Fellows } & 9\end{array}$

Buy-In by the Automotive Industry 9

$\begin{array}{ll}\text { Conclusions } & 9\end{array}$

$\begin{array}{lr}\text { Acknowledgements } & 9\end{array}$ 


\section{Background}

In 1998 the United States Department of Energy (DOE) through its Office of Transportation Technologies (OTT) established the Graduate Automotive Technology Education (GATE) Program. The goal of the Gate Program is:

"To educate a future workforce of cross-disciplinary automotive professionals who are knowledgeable about and experienced in developing and commercializing cutting-edge, advanced automotive technologies."

In order to achieve this goal, the DOE sought to establish GATE centers at select universities across the United States. The initial focus is on hybrid-electric vehicles and proposals were solicited in the following areas:

Hybrid Drive Trains and Control Systems (HDT)

Energy Storage (ES)

Direct-Injection Engines (DI)

Fuel Cells (FC)

Lightweight Materials (LWM)

The schedule called for the universities to use the 1998-99 academic year (AY) to establish the centers and to accept students for the 1999-2000 AY. DOE provided funding in the amount of $\$ 100,000$ for the first year (establishing the center), $\$ 200,000$ for the second year $(\$ 100,000$ for the center operations and $\$ 100,000$ for GATE Fellowships), and $\$ 100,000$ per year thereafter for GATE Fellowships. Thus, for the sixyear program a total of $\$ 700,000$ was budgeted by DOE for each center.

The University of Tennessee, Knoxville, (UTK) was one of nine universities selected to participate in the program. The focus area for the UTK GATE Center is hybrid drive trains and control systems (HDT). Other universities participating and their focus area(s) are:

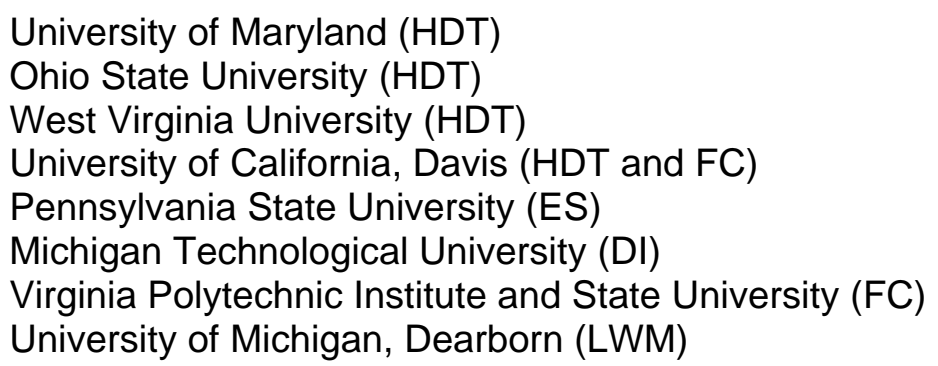

The UTK GATE Center - an Overview

The GATE Center at UTK is housed in the College of Engineering with administrative support (accounting, purchasing, etc.) in the Mechanical, Aerospace and Biomedical Engineering Department. The Center Director, who comes from that department, is responsible for the operation of the Center in consultation with the other GATE Faculty (see below). The Director also makes decisions (in consultation with the other GATE Faculty) regarding the allocation of Fellowships. 
Close working relationships are maintained with the National Transportation Research Center (NTRC), a joint venture between UTK and Oak Ridge National Laboratory (ORNL). As discussed below, several important industrial partnerships have served to benefit the students involved in the GATE Center.

Students who participate in the GATE Program can work towards "GATE Certification" by including a certain number of GATE-related courses in their programs of study and by doing their thesis (or dissertation) in the UTK focus area. At the MS level the number of GATE course hours required is six semester hours (two courses) and at the Ph.D. level the number of GATE course hours is twelve semester hours (four courses).

There are two classifications of UTK GATE students: GATE Fellows (those who receive GATE Fellowships) and GATE Research Assistants (those who are pursuing GATE certification, but do not have a GATE Fellowship). GATE Fellows are expected to mentor undergraduate students working on the DOE-sponsored alternative fuel competition vehicles (FutureCar, FutureTruck and Challenge $X$ ) as part of their responsibilities.

\section{UTK GATE Faculty}

The UTK GATE Center Faculty members are primarily associated academically with either mechanical engineering or electrical engineering. They and their primary technical interests are as follows:

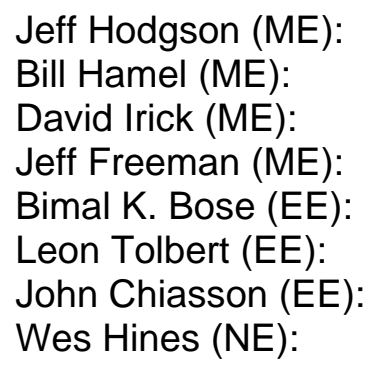

GATE Faculty members are expected to teach courses associated with the GATE curriculum and/or serve as the Major Professor for one or more GATE students.

\section{The UTK GATE Curriculum}

Students enrolled in the GATE Program are typically working towards an advanced degree (MS or Ph.D.) in one of three engineering programs: mechanical engineering, electrical engineering, or engineering science. In order for them to meet the requirement for including certain GATE-related courses in their programs of study, new courses were instituted and offered for both GATE students and students not involved in the GATE Program. These courses address various aspects of hybrid electric vehicle design as follows:

ME 588 (3) Introduction to Hybrid Electric Vehicles (3). Series, parallel, and dual configurations. Sizing and analysis of typical HEV components: motors, auxiliary power sources, on-board energy storage, and fuels. Steady-state HEV force and power 
modeling schemes. Powertrain design using various computer simulation tools. Prerequisite: Consent of instructor

ME 589 (3) Hybrid Electric Vehicle Control Systems Design and Analysis (3). Dynamic modeling, simulation and analysis of complete HEV systems. Linear control design techniques and discrete logic design applied to HEV power trains and operating mode controls. Digital and real-time controls and hardware issues of automotive systems. Design and human factors engineering issues of vehicle controls and displays. Prerequisite: ME 588 or consent of instructor.

ME 689 Hybrid Electric Vehicle Advanced Controls (3). Nonlinear modeling and control issues associated with HEV power trains: fuzzy and neural control techniques. Adaptive and optimal control schemes for vehicle performance enhancement. Review of modern automotive control hardware and software trends and practices. Prerequisite: ME 589.

ME 523 (3) Special Topics in Thermodynamics - Advanced Internal Combustion Engines. Combustion and computer modeling of internal combustion engine processes. Alternative fuels, emissions and emission controls, valve timing. Prerequisite. Undergraduate thermodynamics.

EE 599 (3) Special Topics - Power Electronics and Drives for Hybrid Electric Vehicles. Modern power electronic devices and various electric motor configurations with emphasis on their applications in hybrid electric vehicles. Prerequisite: Consent of instructor.

These courses are offered to accommodate the anticipated demand of the GATE Program. ME 588 and ME 589 are normally offered in the fall and spring semester, respectively, each year. The other courses are offered every other year.

\section{Recruitment of Students}

Students come to the GATE Program in response to the DOE-sponsored web site, the UTK GATE web site, flyers posted locally, solicitations made by examining the list of students accepted for graduate school, presentations made to local graduating students, and the inevitable word-of-mouth. Loss of GATE funding made it necessary to remove the UTK GATE web site as prospective students were being misled by the false information it contained.

It has been our experience that recruiting an adequate number of students has not been difficult and the UTK GATE enrollment has been resource-limited. Although the number of GATE Fellows on board is limited by the available funding from DOE, GATE Research Assistants have been supported by research contracts.

\section{The UTK GATE Students}

As of the end of the 2001-2002 AY, the number of students involved in the GATE Program at UTK had dropped significantly due to the cut in the GATE Program funding made by congress. Since its inception (Fall, 1999) the UTK GATE Program has enrolled twenty two GATE students (thirteen Fellows and ten Research Assistants), eighteen students have graduated, three have completed their course work requirements, and 
one has left the university. The following gives a brief review of the students who have been associated with the GATE Program at UTK.

\section{UTK GATE Fellows}

Thirteen students have enrolled with GATE Fellowships. Of these thirteen, eight have graduated, three have completed their course work and are involved in their research, one transferred to a research assistantship, and one has left the university. Below is a listing of GATE Fellows.

Paul McCown has completed the GATE Program and has graduated with an MS degree in mechanical engineering. His thesis dealt with testing and characterizing the performance of an existing HEV (the UTK FutureCar hybrid electric Intrepid). He is working for a private consulting firm.

Fred Mottley has completed his MS degree in mechanical engineering. His research dealt with testing a new rotary engine design. Mr. Mottley has accepted employment with the Volpe Transportation Center.

David Smith has completed the course work requirements for the Ph.D. degree in mechanical engineering, but left the program early to accept employment with Ford Motor Company to work on the Escape HEV program. Mr. Smith has since returned and is working for Sentech, Inc. while pursuing his Ph.D. research. His research topic has not yet been defined.

Tim Cunnyngham completed his MS degree program in electrical engineering and has accepted a position with the Electric Transit Vehicle Institute in Chattanooga, Tennessee.

Claudell Harvey completed her MS degree in mechanical engineering and is working for a company involved in emission control technology. Her thesis dealt with the design and fabrication of a control system for a dynamometer suitable for testing hybrid electric vehicles.

Alexander Pal has completed his course work for the Ph.D. degree.

Palak Patel has completed his MS degree in mechanical engineering and is now working for Detroit Diesel. His research topic dealt with the performance of a microwave regenerated soot filter for diesel engines.

Tim Norton has completed his MS degree in mechanical engineering. His thesis topic dealt with the use of carbon foam technology for heat transfer applications associated with hybrid electric vehicles.

Aaron Woods also started in the fall of 2001 in the Ph.D. program. He became a parttime student due to the lack of funding to continue his GATE Fellowship and has since left the university.

Weston Johnson has completed his MS degree in electrical engineering. His research involved the design of a novel reluctance motor. 
Gary Holder has completed the course work for the MS degree in mechanical engineering. His research involves modeling, simulation and evaluation of a hybrid electric vehicle.

John Miller has completed his MS degree in mechanical engineering and is employed at Southwest Research Institute. His research involved the design of a single axle series regenerative braking system for a hybrid electric vehicle.

\section{UTK GATE Research Assistants}

Ten students enrolled as GATE Research Assistants. Eight of these, eight graduated with their MS degrees in mechanical engineering, one graduated with his MS degree in electrical engineering, and one graduated with his Ph.D. degree in electrical engineering.

Thang Dam is a U.S. Citizen who immigrated to this country from Viet Nam. He has completed his MS degree in mechanical engineering and is working at the NTRC. His thesis topic dealt with the performance of micro-dilution tunnels in determining particulate emissions from diesel engines.

Burak Ozpineci has received his Ph.D. degree in electrical engineering and is also working at the NTRC. His dissertation topic dealt with the use of silicon carbide power electronic devices in hybrid electric vehicle power electronic applications.

Craig Rutherford has completed his MS degree in mechanical engineering. His research dealt with the conceptual design of a hybrid electric HMMWV. He is employed by Lynx Motor Technologies designing electric motors and applications for them.

Matt Smith has received his MS degree in mechanical engineering and is currently working for Ford Motor Company in the areas of hybrid electric vehicles. His thesis dealt with the design and implementation of a control system for the UTK FutureCar.

Doug Ferguson has received his MS degree in mechanical engineering and is working for The University of Tennessee. His thesis topic dealt with electronic injection controls for diesel engines.

Baskar Vairamohan received his MS degree in electrical engineering. He did his thesis on "State of Charge Estimation for Batteries" and is currently employed with EPRI-PEAC in Knoxville.

M. Rajkumar received his MS degree in mechanical engineering and is entering graduate school to pursue a Ph.D. degree. His thesis dealt with combustion modeling in diesel engines.

Aaron Williams completed his MS degree in mechanical engineering in the summer of 2004. He was originally offered a fellowship, but he was transferred to a research assistantship due to lack of funding. His research dealt with performance of a lean $\mathrm{NO}_{\mathrm{x}}$ trap for natural gas engines. 
Balaji Ramamurthy has completed his MS degree in mechanical engineering and is employed at Rocore. His research dealt with the design of a reverse-flow oxidation catalyst system for lean burn natural gas engines.

Chris Hamilton has completed his MS degree in mechanical engineering. His research dealt with first and second law analyses of advanced combustion modes in diesel engines.

\section{Industrial Interaction}

The UTK GATE Center has had significant support from industrial partners. These are briefly presented below.

\section{FutureTruck and Challenge $X$}

The UTK efforts in the DOE-sponsored FutureTruck and Challenge $X$ competitions were conducted as GATE Center activities with the GATE students providing leadership and mentoring to the undergraduate students. This activity, of course, involved significant support from industry (General Motors, Ford, and the many other partners in these efforts). The involvement of the GATE Center not only provided support for the competition effort, but also allowed our students to become involved with hardware and software that they otherwise would not have had access to.

\section{DaimlerChrysler}

The GATE Center was able to obtain a significant amount of surplus dynamometer and emission testing equipment from DaimlerChrysler when that company relocated its major engine testing activities from Highland Park. The equipment has been used to upgrade the laboratories at both the University and the NTRC.

\section{Visual Computing Systems}

Visual Computing Systems is involved in the DOE-sponsored Automotive Electric Motor Development (AEMD) Program and through the efforts of our GATE Mentor, Mr. Jim Merritt, we were able to provide two students to intern with that company. One of the students (Craig Rutherford) is a GATE Research Assistant and eventually took a full time position with the company. This partnership led to UTK using a Lynx Motion Technology electric motor in the 2000-2001 FutureTruck.

\section{Delphi}

In order to provide support for the AEMD effort, Delphi provided a battery simulator (an AeroVironment ABC-150) to the GATE Center for use in our electric motor and battery testing efforts. This device is capable of delivering and absorbing electric energy in a programmed manner such that it is extremely useful in testing batteries and/or electric motors. 


\section{Fiat America}

Fiat America R\&D provided two 2.4L turbocharged diesel engines for use in our programs. Two GATE students (Palak Patel and M. Rajkumar) used these engines in their research work.

\section{Industrial Ceramic Solutions}

Industrial Ceramic Solutions approached the GATE Center to explore ways in which we might assist them in developing a microwave regenerated soot filter. One of our GATE students (Palak Patel) used this project as the subject for his MS thesis research.

\section{The NTRC}

Although not an industrial entity, the National Transportation Research Center has provided both equipment and student support to help the GATE Center to achieve its objectives. Eight GATE students (Claudell Harvey, Tim Norton, Burak Ozpineci, Thang Dam, Doug Ferguson, Fred Mottley, Chris Hamilton and Aaron Williams) have benefited directly from this partnership.

\section{Value of Resources Obtained}

Since the GATE Center does not act as a conduit for resources brought to the university, the GATE Center does not have an audited list of resources it "owns". It is possible, however, to list resources that were brought to the university as a result of actions taken by GATE faculty that are associated with the GATE Center's focus area and that involved GATE students and faculty. This list includes:

\begin{tabular}{|l|r|}
\hline The GATE Center (DOE) & $\$ 700,000$ \\
\hline CROET Contract NTRC laboratory upgrade & $\$ 290,500$ \\
\hline NSF Faculty Advisor Award & $\$ 20,000$ \\
\hline Hybrid HMMWV (NAC via ORNL) & $\$ 30,000$ \\
\hline Lean burn natural gas engine emissions (NETL) & $\$ 750,000$ \\
\hline Visual Computing Systems (Internship) & $\$ 30,000$ \\
\hline DiamlerChrysler equipment donation & $\$ 400,000$ \\
\hline Delphi (ABC-150) & $\$ 90,000$ \\
\hline FutureTruck seed money and equipment & $\$ 100,000$ \\
\hline The University of Tennessee (laboratory upgrades, ME) & $\$ 40,000$ \\
\hline The University of Tennessee (laboratory upgrades, EE) & $\$ 43,000$ \\
\hline ORNL contract to work on HEV motor control algorithms & $\$ 225,000$ \\
\hline Evaluation of Lightweight Power Generation Systems (ORNL) & $\$ 234,000$ \\
\hline Nano-particle Measurement in Internal Combustion Engines & $\$ 108,000$ \\
\hline Investigation of Advanced Combustion Regimes (US Army) & $\$ 180,000$ \\
\hline Challenge X seed money and equipment & $\$ 150,000$ \\
\hline The University of Tennessee (laboratory upgrades, ME) & $\$ 62,000$ \\
\hline Update and Expansion of the UTK GATE Center & $\$ 620,525$ \\
\hline Total & $\$ 4,073,025$ \\
\hline
\end{tabular}




\section{Support from the University}

The University of Tennessee has been a great supporter of the GATE Center. In addition to the cost sharing provisions of the Cooperative Agreement, the university has provided space for the GATE Center in the Science and Engineering Building and, when DOE funding was cut, the MABE Department picked up the stipends for two of the GATE students (Aaron Williams and Aaron Woods). The University has also provided space and facilities for the students to conduct their work.

The University also provided two separate grants totaling $\$ 102,000$ to upgrade portions of the automotive engineering laboratories.

\section{Other UTK GATE Center Activities}

In addition to providing a mechanism for students to become involved in hybrid electric vehicles, the GATE Center was involved in several other activities:

\section{The UTK GATE Center Dedication Ceremony}

On September 13, 1999 a dedication of the UTK GATE Center was held in the Science and Engineering Building. Dignitaries present who addressed the gathering were Richard Moorer (DOE), U.S. Representative Jimmy Duncan, UTK President Wade Gilley, UTK Chancellor Bill Snyder, and Dean of Engineering Jerry Stoneking.

\section{Hybrid Electric Vehicle Displays}

Students and Faculty from the GATE Center were involved in arranging for the UTK FutureTruck to be displayed as part of larger events. These included the 2001 SAE Congress in Detroit, the Coil Winders Association in Indianapolis, homecoming at UTK, and the NTRC open house.

\section{Hybrid Electric Vehicle Seminar}

Professors Hodgson and Hamel presented a one-day seminar in Huntsville, Alabama to U.S. Army personnel dealing with hybrid electric vehicle technology.

\section{Summer Kids Program}

Under the direction of Craig Rutherford, several of the GATE students participated in putting on a multi-day program on hybrid vehicles for junior high school aged students. As part of the program the children built small hybrid electric vehicles and competed against each other

\section{TAMA Seminar}

Six representatives from the Tennessee Automotive Manufacturer's Association (TAMA) came to the GATE Center for a briefing on the Center's activities and to learn 
more about HEVs. Professors Hamel and Hodgson, with the assistance of several GATE students, conducted the briefing.

\section{Problems Encountered}

Although the UTK GATE Center has been successful in producing crossdisciplinary automotive engineering professionals who are knowledgeable about and experienced in developing cutting edge, advanced automotive technologies; the process has not been as effective as it might otherwise have been. There are several areas in which improvements could be made if the GATE Program is to continue.

\section{Funding Uncertainties}

The lag between the GATE Center operation and the receipt of funding to cover that period has been a problem. Basically the universities involved have had to commit fellowships to students without assurances that the funding to cover these fellowships would be forthcoming. We understand that DOE was taken to task by the congress for covering these costs without the proper congressional authorization (and all the GATE Centers appreciate the willingness of DOE to stand behind the Centers), but the reality of graduate student recruitment for the GATE Program is that offers of Fellowships have to be made nine months before the start of the academic year. Since the appropriation process was often not complete until after the AY started, the various GATE universities had to "borrow" funds to support the GATE Fellowships with no clear assurances that these funds would be repaid. During AY2002, offers made to two students were underwritten by the MABE Department because GATE funding was withdrawn by DOE.

\section{Research Support for Fellows}

One of the really attractive attributes of a GATE Fellowship is that the GATE Fellow does not have to rely on a funded research project to provide his or her stipend. This means that Fellows can choose research topics that are of greatest interest to them, rather than to be restricted by research topics that are externally funded. However, there are no GATE funds available to support the non-stipend costs of such research and this can be an impediment to Fellows being able to conduct research in their areas of strongest interest. It would be extremely valuable if the GATE stipends could be accompanied with research funding.

\section{Buy-In by the Automotive Industry}

Although the stated objective of the GATE Program is to provide trained professionals for the automotive industry, it was our experience that the GATE Program was not well known in the industry. This was reflected in both the lukewarm support for GATE funding in the congress and in the apparent lack of knowledge about the GATE Program that was revealed in discussions with automotive professionals.

\section{Conclusions}

The UTK GATE Center has been an extremely valuable addition to the College of Engineering. In addition to involving twenty two GATE students, the GATE Center

has provided a focal point to bring together mechanical and electrical engineering faculty and students. The center has led to internship opportunities, opportunities for 
collaboration with other organizations, and has brought additional resources into the automotive systems activities at the University of Tennessee.

\section{Acknowledgements}

The UTK GATE Center would like to express its deep appreciation to the DOE for making the program a reality. We would like to especially thank Tom Gross, Shelley Launey, JoAnn Milliken, and Nancy Garland of DOE for nurturing the program during the

first years of operation. We would also like to thank Jim Merritt, our mentor, for his interest and encouragement.

Finally, we acknowledge the enthusiastic support we received from the late Jerry Stoneking, Dean of Engineering. Without the support of all these people the GATE Program and, in particular, the GATE Center at UTK would not have happened. 